\title{
El Espejo de mi Tierra
}

$\boldsymbol{T}^{L}$ Espejo de mi Tierra fué un "periódico de costumbres", ínE tegramente escrito por don Felipe Pardo y Aliaga. Y, a pesar de su tono satírico, lo apreciamos hoy como un testimonio de inapreciable valor para el recuerdo de los aspectos pintorescos que la vida limeña ofrecía en su tiempo. Como un juicio, a la vez retozón y amargo, pero siempre fino y bien intencionado.

"No se imaginen los curiosos que en este periódico van a encontrar artículos contra el gobierno, ni artículos a favor del gobierno, ni dentrestos al juez porque se ha perdido un pleito, ni ataques al honor o a la tranquilidad del prójimo, ni chismografía de ningún género. El periódico y su prólogo no abrazan más que los objetos generales que pueden comprenderse bajo la denominación de costumbres". 1 Tal decía Felipe Pardo y Aliaga, anunciando al público la inminente aparición de su periódico. $\mathrm{Y}$ su limitación a la pintura de nuestras costumbres fué para unos la clave de su resonancia, el eje de su gracia, la razón de su amena profundidad, o fué, para otros, el efecto de una subjetiva contraposición entre las refinadas costumbres de otrora y la intensa espontaneidad de los nuevos días. Así, El Espejo de mi Tierra ha suscitado una polémica que hasta hoy no se encuentra clausurada. $Y$ esto le da una especial significación en la historia de la literatura peruana: porque es una de las pocas 
obras cuyo estudio se ha volcado hacia su raigambre politica y social, sin quedar restringido a la simple apariencia formal.

Ya, en su tiempo, provocó el apasionado ataque de los criollistas. $2 \mathrm{Y}$, siempre, la censura franca o encubierta contra su "españolismo". "El Espejo de mi Tierra representa la tendencia colonialista y españolizante contra la espontaneidad criolla" - afirma Luis Alberto Sánchez. 3

$\mathrm{O}$, basándose en la descollante actuación pública de don Felipe Pardo y Aliaga, se ha visto en El Espejo de mi Tierra la manifestación literaria de sus ideas políticas. Como lo hace ver Manuel González de la Rosa, "nuestro poeta se hallaba de tal manera dominado por el deseo de amoldar el país a sus ideas de gobierno, que, cuando no gobernaba, consolábase con expresar esas mismas teorías en forma poética, cuando no en prosa, como en el famoso Espejo de mi Tierra, que tuvo un éxito portentoso, y fué como la despedida del escritor satírico, que poco después veíase reducido a la inacción por larguísima dolencia". 4 Pero la insistencia en sus ideas de gobierno ha empalidecido con el transcurso del tiempo. Y el costumbrismo de Pardo nos parece una burlesca confesión de sus desengaños políticos. Una dolida manifestación de la resistencia que sus esfuerzos correctores hallaron en la idiosincracia nacional, antes que consoladora e indirecta expresión de sus ideas. Comprobación de la arraigada fidelidad con que las gentes cultivaban las costumbres de la tierra, antes que añoranza de los usos alejados por el tiempo y la distancia. Y, matizando el alegre colorido de las costumbres criollas, en segundo plano, aflora la nota amarga, inspirada por los contrastes que ofrecían la realidad y el dictado de la ley, la indolencia colectiva y las necesidades del país. La nota amarga, que denuncia la falta de correspondencia entre las virtudes que la fama atribuía a los hombres y su baja condición humana, o su fácil reversibilidad; que pinta, sinceramente, la ponderativa y alharaquienta ingenuidad del carácter criollo. Las ideas de gobierno se presumen a través de los cuadros de costumbres o aparecen como un telón de fondo, y sólo adquieren relieve en la "Constitución política", donde efectivamente se muestra aristocratizante, antirrepublicano y españolista.

"Pardo andaba totalmente reñido con la democracia" - sostiene Luis Alberto Sánchez, insistiendo en el politicismo de El Es- 
pejo de mi Tierra. "Ia república y el militarismo concitaban sus más violentos ataques y sus más agudos epigramas. Acertó en el diagnóstico, pero no en la curación. Sí, es verdad, vivíamos una republiqueta risible, pero habíamos dejado la colonia degradante". $5 \mathrm{Y}$ añade que "su nostalgia conservadora y dinástica era la de un sector considerable de la alta sociedad limeña. Expresión de ella, su airón y su emblema, sobre Pardo llueven los elogios de los simpatizantes de la colonia y los dicterios de los demoliberales. Su estilo cautiva a los clasicistas - cultores literarios del conservadorismo- y molesta a los novadores y popularistas". 6

Por su parte, Ventura García Calderón aparenta comprender estas razones, y admite que "su condición de aristócrata, de semiespañol, de godo y pelucón, lo hiciera sospechoso de antipatía al nuevo medio". Pues, por su educación española, por sus pujos de aristócrata, él no estaba a tono con la reciente y efervescente realidad republicana de su patria. Trasuda un ingénito desdén, que la convivencia de muchos años iba a modificar". $7 \mathrm{Y}$, sin embargo, no deduce las consecuencias. Esta admisión es sólo un esguince, o una constatación de erudito. $\mathrm{Y}$ su elegante ligereza prefiere insistir en el aspecto formal de El Espejo de mi Tierra. Sigue una orientación manida, y destaca la gracia y la oportunidad que caracterizan el estilo empleado por don Felipe Pardo y Aliaga, su inspiración moral, o su aliento educativo. Dice que: "Los capítulos de su periódico están escritos en prosa desenfadada y zumbona, entremezclada de reflexiones ladinas, de retruécanos y de esos giros de lisura tan llenos de languidez que son al mismo tiempo burla y caricia". $8 \mathrm{Y}$ añade: "El Espejo de mi Tierra viene a ennoblecer el género de publicaciones satíricas, que suele ser chocarrero en los comienzos de la era republicana, y precede a toda una serie de revistas chispeantes que será preciso exhumar un día para extraer de ahí veneros de ingenio. evaporado. En'su Espejo, Pardo muestra a las claras su intención moralizadora, que hoy se nos antoja un tanto candorosa". 9

Otros críticos - como el propio Ventura García Calderónrehuyen la polémica. Pero aclaran las interpretaciones que no satisfacen su criterio, exaltan los valores que las ajenas opiniones censuraron, revelan una virtud donde alguien creyó ver pasión discutible. 
Y, en realidad, hacen una defensa tácita. "El Espejo no necesita de apología para los sensatos, y en vano es trabajar para los que no lo son" - dirá uno de sus contemporáneos; 10 "en él se ponen en ridículo los pocos defectos que aún existen y se ensalza lo bueno que se posee; en él se procura inspirar la decencia y estimular a que se adquieran mejoras útiles; en él, en fin, se ve una de aquellas obras capaces de lucir entre las de Larra y Mesonero, y que no puede dejar de distinguirse, porque la providencia ha dado a su autor una imaginación de extraordinaria viveza y felicidad".

Con menos entusiasmo, pero imprimiendo a sus palabras el convencimiento del amor filial, Manuel Pardo Althaus estima que los artículos de El Espejo de mi Tierra, como "cuadro fiel y acabado de las costumbres de aquella época y a la vez crítica chistosa de ellas, se conservarán siempre por el recuerdo que encierran, por la ligereza de estilo, el colorido de la descripción y la gracia con que están escritos y por la influencia que ejercieron en la sociedad de entonces, cuyos hábitos, representantes de su estado social y de 1a historia de sus últimos años, eran un mosaico extravagante de hábitos nuevos incrustados con trabajo en la piedra de las costumbres coloniales". 11

En conclusión, es posible establecer que, por haberse educado en España, don Felipe Pardo y Aliaga no podía sufrir el relativo primitivismo de las costumbres que durante su época predominaron entre nosotros. Deseaba corregirlas. Y -como estima Luis Alberto Sánchez- "se denuncia en un título: El Espejo de mi Tierra. El quisiera serlo, mas no lo consigue: espejo deformador, caricaturista, no refleja sino que abulta. Espejo es pasividad: el de Pardo fué reactividad. Sólo cuando describe costumbres de alta clase, de aristócratas o altoburgueses, logra ser especular; por ejemplo, el caso del 'Niño Goyito'." 12

Por su educación y su experiencia, Pardo quiso presentarse como el ejemplo que se debería imitar. Quiso convertirse en orientador de las costumbres locales. $Y$, al respecto, son elocuentes aquellos versos de Quevedo, que le sirvieron de apotegma:

Señoras, si aquesto propio os llegare a suceder, 
arrojar la cara importa,

que el espejo no hay por qué. 13

Son elocuentes, pues a través de ellos dió a entender que la fealdad de las costumbres presentadas y criticadas en el periódico debía aconsejar el aborrecimiento de ellas, mas no la diatriba contra éste, que sólo era su "espejo". Dió a entender que el "espejo" debía mantenerse ante la vista, como un testimonio que presentaba las imágenes corregibles. Cómo había concebido aquella "sátira afinada y escéptica" 14 que fué El Espejo de mi Tierra, aquella sátira que hoy nos revela su activa $-\mathrm{y}$, por lo tanto, política- disconformidad con la época en que vivía.

Aunque se le ha conocido mal, o deficientemente, El Espejo de mi Tierra ha sido muy citado. $\mathrm{Y}$, a veces, con flagrantes errores $\mathrm{u}$ omisiones.

Por ejemplo, Mariano Felipe Paz Soldán no menciona el tercer número, ni especifica el número de páginas que tuvieron el prospecto $\mathrm{y}$ el alcance al número segundo. 15

Luis Alberto Sánchez nos dice que Pardo "se destacó por su manera de satirizar las costumbres criollas, tanto en la "Constitución Política', poema burlesco, como en las costumbres retratadas en El Espejo de mi Tierra"; 16 olvida que la "Constitución política" es sólo una parte de El Espejo de mi Tierra, pues apareció en su tercer número. Reincide en el mismo olvido cuando sostiene que Pardo "dirige sus sátiras contra el Estado y contra cierta aristocracia sedentaria en las páginas de la 'Constitución Política' y de El Espejo de mi Tierra". $17 \mathrm{Y}$ atribuye dos títulos a un trabajo - “sólo cuando describe costumbres de alta clase, de aristócratas o altoburgueses, logra ser espectlar; por ejemplo, el caso del 'Niño Goyito', 'Un viaje" "18 - porque no recuerda que el niño Goyito es el protagonista de "Un viaje".

En verdad, El Espejo de mi Tierra apareció con la frecuencia que se observa en el siguiente cuadro: 


\begin{tabular}{|c|c|c|c|c|c|}
\hline \multirow{2}{*}{$\begin{array}{l}\text { Námero } \\
\text { de orden }\end{array}$} & \multicolumn{3}{|c|}{$\mathbf{F} \mathbf{E} \mathbf{C} \mathrm{A}$} & \multirow{2}{*}{$\begin{array}{l}\text { i Número } \\
\text { de páginas }\end{array}$} & \multirow{2}{*}{ Observaeiones } \\
\hline & Año & Mes & Día & & \\
\hline Prospecto & 1840 & $\ldots$ & $\ldots$ & $\mathrm{I}-\mathrm{XVI}$ & $\begin{array}{l}\text { Sin fecha. Debió apa- } \\
\text { recer el } 10 \text { de sep- } \\
\text { tiembre de } 1840 \text {, } \\
\text { conforme se dedu- } \\
\text { ce por un aviso } \\
\text { publicado en } E l \\
\text { Comercio. }\end{array}$ \\
\hline 1 & $\ldots$ & Setiembre & 22 & $1-24$ & \\
\hline 2 & $\ldots$ & Octubre & 8 & 25.48 & 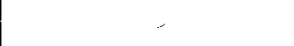 \\
\hline Alcance al & & & & & \\
\hline Núm. 29 & $\ldots$ & $\ldots$ & $\cdots$ & 1.5 & $\begin{array}{l}\text { Escrito por don Feli- } \\
\text { pe Pardo. antes de } \\
\text { dirigirse a Valpa- } \\
\text { raíso, al leer el pri- } \\
\text { mer número de } \\
\text { Lima contra El Es- } \\
\text { pejo de mi Tietra. }\end{array}$ \\
\hline 3 & 1859 & Marzo & 31 & 1.30 & \\
\hline
\end{tabular}

Además de las páginas correspondientes al texto, cada número tenía una portada, impresa en papel de copias, de diverso color. $\mathrm{Y}$, en ella, como apotegma inspirador, se insertaban los ya citados versos de Quevedo.

Se imprimió en la imprenta de José Macías (calle de la Pescadería, $\mathrm{N}^{\circ}$ 127). Excepto el alcance al número segundo, que fué editado en la Imprenta del Comercio, por J. M. Monterola.

Cada número costaba 4 reales. Pero el prospecto y el alcance al número segundo se vendieron a 2 reales, en atención a su reducido número de páginas.

Total o parcialmente, las poesías y los artículos contenidos en El Espejo de mi tierra han sido transcritos en las siguientes publicaciones: 
1. Poesías y escritos en prosa de don Felipe Pardo, miembro correspondiente de la Real Academia Española, y Honorario de la Facultad de Humanidades de la Universidad de Chile. París, Imprenta de los Caminos de Hierro, A. Chaix et Cie., 1869. xxxv y 514 pp., folio.

2. Poesias de Felipe Pardo, precedidas de su biografía y acompañadas de algunas notas por Manuel González de la Rosa. ParisMéxico, Librería de la Vda. de Ch. Bouret, 1898. 386 pp., $4^{\circ}$

3. El Atenéo de Lima, No 17. Lima [? ] de 190[?].

4. Del romanticismo al modernismo (prosistas y poetas peruanos). Ed. Ventura García Calderón. París, Sociedad de Ediciones Literarias y Artísticas, s/f., [1910], 545 pp., 4?

5. Parnaso perviano, ordenado por Ventura García Calderón. Segunda edición. Barcelona, Casa Editorial Maucci, s/f., 319 pp., $4^{9}$

6. El paseo de Amancaes y otros escritos, por Felipe Pardo. La Literatura Peruana, año I, vol. II, Lima, 12 de abril de 1923. 32 pp., 4\% mayor.

7. Costumbristas y satiricos. Biblioteca de Cultura Peruana, t. 9, vol. I. París, Desclée de Brouwer, 1938. 343 pp., 49.

$$
\begin{gathered}
* * * \\
\text { Prospecto }
\end{gathered}
$$

Prólogo (pp. 1-16)

Dice que "la brusca transición del coloniaje a la independencia, ha grábado en las costumbres el mismo carácter de instabilidad, que afecta a todas las cosas en semejantes crisis. Las costumbres nuevas se hallan todavía en aquel estado de vacilación y de incertidumbre, que caracteriza toda innovación reciente: las antiguas flaquean por sus cimientos al fuerte embate de la revolución. ¿Qué coyuntura más favorable para los escritores que quieren mejorarlas?" Por lo tanto, se propone criticar nuestras costumbres, para contribuir a su mejoramiento. Y, anticipándose a las censuras mal intencionadas, pide que la publicación de su periódico no sea mirada como el fruto de "una disposición malévola a maldecir del pais".

Puede verse en:

1. pp. 319-326: 


\section{Nimero 1}

El paseo de Amancaes (pp. 1-19).

Sabrosa descripción del tradicional paseo que los limeños verifican a la Pampa de Amancaes, el 24 de junio. Destaca la agitada minuciosidad de los preparativos; menciona viandas y bailes típicos; alude a lo "fastidioso" de ciertos cantares populares. $Y$ todo esto lo entreteje con reflexiones sobre las costumbres de la época. Sobre la educación de la mujer, dice: "sin colegio, con malos maestros, y sin una norma segura de lo que llamaré buen tono... formaba uno de aquellos seres privilegiados, que tienen la gracia de suplit, por una especie de inspiración celestial, las imperfecciones de la educación". Y sobre el individualismo criollo, agrega: "Si eres clérigo, tu amigo clérigo te deseará tódo, menos la canongía vacante. Si sois ambos literatos, una obra tuya aplaudida será para éł un tósigo que le devorará las entrañas. Si eres rico, ningún encargo tuyo desempeñará con más gusto que el de tu albacea".

Puede verse en:

1. pp. 327-336.

6. pp. $3-16$.

7. pp. $166-184$.

Mi prólogo (pp. 21-24).

Glosa y comenta las diversas reacciones que entre el público limeño había producido el prólogo. Se dirige a los editores de El Comercio porque "han escitado mi profundo reconocimiento al emitir en su periódico un juicio tan ventajoso de mis escritos y de mi capacidad".

Puede verse en:

1. pp. 337-339.

\section{Número 2}

Opera y nacionalismo (pp. 25-38).

Reflexionando en torno al nacionalismo, lo cree una necedad, pues considera al Perú y sus vecinos como miembros de "la antigua familia hispano-americana". "El verdadero nacionalismo es el que se constituye en centinela" del honor, la libertad y la independencia nacionales; el que sabe "conciliar el amor a nuestros derechos con el cumplimiento de nuestros deberes, el celo por nuestros inte- 
reses nacionales, con la amistad hacia todos los individuos que no han nacido en la misma porción territorial que nos ha cabido en suerte". No es un nacionalismo verdadero el que se basa en el "aislamiento y la limitación exagerada de nuestra patria". Justamente zahiere la incondicional adhesión a ciertos usos extranjeros. $Y$ concluye con minuciosa crítica de la temporada lírica que Lima gozó en 1840 .

Puede verse en:

1. pp. 340-347.

El suicidio (pp. 39-44).

Canción humoristica, inspirada por la filosófica resignación con que sufrió "uno de sus destierros". Está compuesta en versos octosilabos y tetrasilabos.

Puede verse en:

1. pp. $47-49$.

Un viaje (pp. 45-48).

Estando a punto de embarcarse a Chile, Felipe Pardo escribe este artículo para sustituir la "visita o tarjeta de despedida" que era de rigor en estos casos. $\mathrm{Y}$ nos brinda una sátira contra la manera como viajarian "muchos de la generación actual, que conservan el tipo de los tiempos del virrey Avilés" (1801-1806); contra el "niño engreído de familia rica, mimado por las eternas tías castizas" - como apunta Lùis Alberto Sánchez.

Puede verse en:

1. pp. 348-350.

4. pp. $81-85$.

6. pp. 17-19.

7. pp. $162-165$.

\section{Alcance al número 2}

Al autor del folleto publicado con el título de "Lima contra el Espejo de mi Tierra" (pp. 3-4).

Juzgando al hombre por el estilo, concluye que el autor del citado folleto es: ignorante; de medio pelo, y aun negro; muy mal hablado; hombre que se mete a hacer lo que no sabe.

Puede verse en:

3. p. 454. 
El tamalero (pp. 4-5).

Letrilla satírica en la cual intercala algunas frases en el caló de los negros, para hacer burla del autor de Lima contra el Espejo de mi tierra.

Puede verse en:

3. pp. $455-456$.

7. pp. $184-186$.

\section{Número 3}

Advertencia (pp. 1-6).

Presentando su poema satítico sobre la constitución del Perú, dice que éste es un pais "en donde raros son los que no se creen capaces de vaciar en veinticuatro horas el mejor código fundamental que pueda salir del molde legislativo, decidiendo magistralmente las más intrincadas cuestiones de la ciencia administrativa". Afirma que "la mejor constitución de un pueblo no es la más engalanada con el falso relumbrón de doctrinas fantásticas, sino la que le permite caminar con más desenvoltura y con más seguridad por la senda del progreso". Y pretende que en su sátira está la propia "constitución de la República, despojada de la engañifa de los cosméticos, de la crinolina y del corsé".

Puede verse en:

1. pp. $99-100$.

2. pp. $215-218$.

Constitución politica (pp. 7-30).

Poema satírico, compuesto en octavas reales. Estuvo destinado a servir como instrumento de propaganda, contra la constitución liberal de 1856; pero, aparte de la crítica a sus principales títulos, presenta una cruda visión de la realidad nacional.

Después de haberlo publicado en El Espejo de mi Tierta, Felipe Pardo le agregó algunas octavas a este poema, y así aparece en su colección de Poesias y escritos en prosa.

Puede verse en:

1. pp. 101-111.

2. pp. $218-250$.

4. pp. 79-81. Sólo inserta los capítulos IV y VIII, correspondientes a "Ciudadania" y "Poder Ejecutivo". 
5. pp. 19-21. Sólo inserta los capítulos IV y VIII, correspondientes a "Ciudadania" y "Poder Ejecutivo".

7. pp. 138-161.

\section{Alberto Tauro,}

Lima.

\section{NOTAS}

1 El Comercio. Lima, 9 de setiembre de 1840.

2 Véase Lima contra El Espejo de mi Tierta, periódico que Mariano Felipe Paz Soldán describe en los siguientes términos: "eventual, en 40. Lima 1840: redactor Bernardo Sófia y colaborador el poeta D. Manuel Segura: salieron dos números: el 19 con 16 páginas de 148 por 088 , el $2{ }^{\circ}$ con 17 páginas, y un alcance sin fecha". ("Biblioteca Peruana"; en Revista Peruana, vol. II, p. 232. Lima, 1879).

3 Luis Alberto Sánchez, Historia de la literatura americana (desde los origenes hasta 1936). Santiago de Chile, Ediciones Ercilla, 1936. (p. 212).

4 Véase Poesias de Felipe Pardo, precedidas de su biografía y acompanadas de algunas notas por Manuel González de la Rosa. París-México, Librería de la Vda. de Ch. Bouret, 1898.

5 Luis Alberto Sánchez, Historia de la literatura peruana ("La república"). Tirada aparte de Atenea. Santiago de Chile, Universidad de Concepción, 1936, (p. 97).

6 Ibidem, p. 99.

7 Ventura Gatcía Calderón, Costumbristas y satíticos. Biblioteca de Cultura Peruana, t. 9, vol. I. París, Desclée de Brouwer, 1938.

8 Ventura García Calderón, Del romanticismo el modernismo (prosistas y poetas peruanos). París, Sociedad de Ediciones Literarias y Artísticas, s/f. (1910). tado.

9 Ventura García Calderón, Costumbristas y satíticos, volumen ci-

10. Juan Antonio Ugarteche, en carta dirigida a los editores de El Comercio. Lima, 17 de octubre de 1840.

11 En Poesias y escritos en prosa de don Felipe Pardo. París, Imprenta de los Caminos de Hierro, A. Chaix et Cie., 1869. (p. xxiii). 
12 Luis Alberto Sánchez, Historia de la literatura peruana ("La república") (p. 96).

13 Refiriéndose a El Espejo de mi Tierta, estos versos han sido glosados por José Jiménez Borja en Cien años de literatura $y$ otros estudios criticos, editado por Pedro Barrantes Castro. Lima, 1940, (p. 5).

14 Javier Prado y Ugarteche, "Las letras en la vida intelectual de la República en el siglo XIX". Boletín de la Academia Peruana correspondiente de la Real Española de la Lengua, t. I, cuaderno I. Lima, enero de 1918. (p. 133).

15 En su "Biblioteca Peruana" inserta la siguiente referencia: "Espejo de mi Tierra (EI), de costumbres, eventual, de 162 por 132, en 40. Lima 1840: por don Féipe Pardo, núm. 1 ㅇ el 22 de Setiembre de 1840 y terminó con el núm. 2 el jueves 8 de Octubre de 1840, más un alcance y el prospecto. Cada número tiene 24 páginas". (Revista Petuana, vol. II, p. 75, Lima, 1879).

16 Luis Alberto Sánchez, Histotia de la litetatura ameticana (desde los origenes hasta 1936). Ediciones Ercilla, 1936. (p. 219).

17 Luis Alberto Sánchez, La literatura del Perá. Buenos Aires, Imptenta de la Universidad de Buenos Aires, 1939. (p. 96).

18 Luis Alberto Sánchez, Historia de la literatura peruana ("La repáblica"). (p. 96). 